\title{
Análisis iconográfico de la publicidad audiovisual de perfumes
}

\section{El caso de J'Adore}

\section{Iconographic analysis of perfumes audiovisual advertising. The case J'Adore.}

Paloma Fernández Fernández

Directora Académica Grado en Publicidad y Profesora contratada doctor (Universidad Francisco de Vitoria de Madrid)

\section{Miguel Baños González}

Profesor Titular de Universidad

(Departamento: Ciencias de la Comunicación II, Universidad Rey Juan Carlos)

\section{Francisco García García}

Catedrático de Universidad de Comunicación Audiovisual y Publicidad (Universidad Complutense de Madrid)

Fecha de recepción: 03 de noviembre de 2012

Fecha de revisión: 25 de abril de 2013

Para citar este artículo: Fernández Fernández, P., Baños González, M., García García, F. (2014): Análisis iconográfico de la publicidad audiovisual de perfumes. El caso J'Adore, Icono 14, volume (12) , pp. 398-430. doi: 10.7195/ri14.v12i1.549 


\section{Resumen}

La publicidad como crisol en el que se combinan elementos de nuestra cultura visible con conceptos e imágenes inconscientes, es analizada en esta investigación para conocer los elementos retóricos y narrativos que posibilitan que el mensaje sea más completo y universal que el anuncio de un producto o marca. En los anuncios del sector de la perfumería se aprecian relatos de gran complejidad que, siguiendo la teoría de los arquetipos de C. G. Jung, se concretan en modelos humanos intemporales. El modelo de análisis desarrollado se aplica al caso del anuncio del perfume J'Adore de Dior emitido entre 2008-12, evidenciando la utilización de recursos estilísticos y retóricos en un relato que se construye en torno al mito de Afrodita como materialización del concepto de la creatividad a través de la belleza y la sensualidad. El modelo de análisis analiza el contenido y la forma del discurso publicitario.

\section{Palabras clave}

Arquetipos - Iconografía - Mensaje audiovisual - Narrativa - Perfume - Publicidad Retórica - Relato

\section{Abstract}

Advertising as a crucible in which elements of our visible culture with concepts and unconscious images are combined, is analyzed in this research for rhetorical and narrative elements that enable the message to be more complete and universal that the announcement of a product or brand. In advertisements perfumery industry stories of great complexity, on the theory of archetypes appreciate $C$. G. Jung, are specified in timeless human models. The developed model is applied to the case analysis Ad J'Adore Dior fragrance issued between 2008-12, showing the use of stylistic and rhetorical resources in a narrative that is built around the myth of Aphrodite as the embodiment of the concept of creativity through beauty and sensuality. The analysis model analyzes the content and form of advertising discourse.

\section{Key Words}

Archetypes - Iconography - Audiovisual message - Narrative - Perfume - Advertising - Rhetoric - Story. 


\section{Introducción}

La publicidad se produce y se consume en un contexto concreto, dentro del cual trasciende su propia vocación comercializadora de productos y servicios, enriqueciendo sus mensajes con todos los recursos que tiene a su alcance $\mathrm{y}$, al mismo tiempo, capta las fórmulas nuevas de expresión y comunicación. Podríamos considerar la publicidad como un crisol en el que el producto y la marca se encuentran con la cultura dominante en la sociedad en la que se emite y sobre la cual la publicidad actúa en un proceso de interacción continua.

Con frecuencia, la publicidad articula su lenguaje en torno a lo obvio, reproduciendo escenas de vida, mientras que en los anuncios más celebrados se construye el mensaje con un discurso entre sorprendente, paradójico y sugerente, valiéndose de la retórica, de las referencias a la culturas clásicas y contemporáneas... todo con el objetivo de reforzar el contenido y mejorar su efecto en el público al que se dirige.

A pesar de su aparente simplicidad, un análisis en profundidad pone de relieve que los mensajes publicitarios, al menos los que han despertado más interés entre el público, muestran una estructura narrativa muy cuidada en la que tanto lo que se narra, la historia, como la forma en la que se narra, la articulación específica de los elementos para expresar la historia, presentan unos niveles de elaboración muy precisos. La potencialidad de la imagen, la palabra, el relato... no serían nada sin una narración que vertebre todos los elementos y se enriquezca con recursos expresivos procedentes de los territorios del lenguaje visual, icónico, simbólico, gestual y por supuesto, verbal.

En este trabajo, extraído de la tesis doctoral titulada Mitos y arquetipos en los mensajes publicitarios de perfumes (Fernández, 2010), co-dirigida por García F. y Baños, M., mostramos un estudio en profundidad del mensaje publicitario audiovisual a través de tres análisis específicos: retórico, narrativo e iconológico, con el fin de obtener unos resultados que muestren la heterogeneidad de elementos expresivos y significativos que nutren el mensaje persuasivo, aportando un enfoque distinto al estudio del mensaje publicitario que se centra más en el contenido, y 
en concreto, en el análisis de los recursos retóricos, expresivos e iconológicos que se ponen en juego en piezas publicitarias tan ricas en significado como las de la publicidad del sector de la perfumería de lujo. En la tesis doctoral referenciada se clasificaron un total de 150 anuncios de perfumes en 12 categorías correspondientes a 12 arquetipos de la mitología griega y se analizó en profundidad uno de cada grupo, siendo el que aquí presentamos el analizado para el arquetipo de Afrodita, diosa de la creatividad y la sensualidad, elegido para este artículo porque todavía se sigue exhibiendo en campañas publicitarias de la marca J'Adore de Dior.

El propósito de este trabajo es conocer la raíz de la que emanan las historias que articulan los relatos publicitarios de perfumes; Pretendemos establecer si las características propias de los arquetipos definidos por C. G. Jung (2002) como estructuras humanas preconscientes, representadas por los dioses mitológicos griegos, siguen estando vigentes en la sociedad actual, con las lógicas adaptaciones culturales, a través del análisis de los mensajes publicitarios de perfumes.

\subsection{Teoría de los arquetipos}

Los arquetipos fueron definidos por C. G. Jung (2002) como estructuras innatas de la psique que operan en el individuo de manera inconsciente y que determinan su experiencia social. El arquetipo funciona como una estructura innata del individuo y, con ese sustrato, las distintas sociedades construyen sus cosmogonías, que son aceptadas, con ligeras variaciones locales, por otras culturas, transformándose con el paso del tiempo, pero manteniendo su esencia original.

Los arquetipos no se heredan individualmente sino colectivamente, por lo que hablaremos del inconsciente colectivo como el espacio virtual en el que determinados arquetipos se han ido identificando, constituyendo todos ellos lo que podría explicarse diciendo que la naturaleza en la que el hombre vive está estructurada de forma que el ser humano puede comprenderla a partir de imágenes análogas que a lo largo de los tiempos se repiten.

ICONO14 | Año 2014 Volumen 12 NN $^{\circ}$ | ISSN: 1697-8293 | DOI: ri14.v12i1.549 
Según mi experiencia, a la conciencia sólo puede concedérsele una relativa posición media, y tiene que soportar el ser circundada y dominada por todas partes por la psique inconsciente. Por los contenidos inconscientes está ligada hacia atrás, de un lado, con las condiciones fisiológicas $y$, de otro, con los presupuestos arquetípicos. Pero también se anticipa hacia adelante por intuiciones.

(Jung, 1950, p. 193)

La causa formal, en términos aristotélicos, que provocaba esos contenidos era para Jung, de naturaleza arquetípica. Este concepto había sido formulado anteriormente por Jung, basándose en profundas intuiciones de Freud e inspirándose en el vocabulario clásico platónico.

La existencia de los arquetipos ha sido constatada por C.G. Jung (1950) por la evidencia de que se dan imágenes arquetípicas, y sólo estas últimas pertenecen al terreno de la observación, mientras que los arquetipos se deducen de ellas. Estas imágenes tienen una significación cultural que puede ser variable para el individuo, en función de su experiencia personal, y para el conjunto de una civilización o incluso para la Humanidad; Jung denominó símbolos generales y símbolos universales, a esas imágenes que, más allá de la variaciones culturales, otorgan un significado inconsciente y universal al árbol, el río, el mar, la caverna, la cruz....

Los arquetipos esenciales, según el mismo autor, son el sí-mismo, la sombra, el ánima y el ánimus. Estos cuatro arquetipos son las 4 coordenadas básicas sobre las que se estructura la personalidad del ser humano; a partir de ellos, C.G. Jung (2002) identificó los prototipos sociales que, de forma resumida y esquemática, podemos observar en los dioses de la mitologías occidentales, especialmente la griega y la romana clásicas.

Los relatos míticos tienen su correspondencia con los denominados contenidos "arquetípicos" por C.G. Jung. Como estructura profunda del inconsciente colectivo, estos mismos arquetipos se han constelado en personajes concretos a lo largo de 
la historia, como los protagonistas del panteón romano y griego, que tienen también un precedente en culturas más antiguas, que sin embargo se pierden en sus múltiples versiones, hasta la edad en que el cristianismo se erigió como religión hegemónica de Europa, lo que permite aventurar que, a pesar del tiempo de silenciamiento, la teoría jungiana de sistemas arquetípicos preexistentes en el inconsciente del individuo, actúan como "esquemas básicos" o referencia universal de prototipos ideales o modelos originales de personas, que a través de su representación iconográfica, se convierte en una convención social, en una interpretación simplificada de un personaje.

Esta preexistencia básica de los mitos, así como su simplificación y reiteración en diferentes culturas, permite suponer su pervivencia hasta la actualidad de forma completa o parcial, y la posible influencia que sigue ejerciendo en algunos ámbitos como el artístico, del que la publicidad participa en su vertiente de creadora de imágenes que transmiten atributos de los productos o marcas, por medios que no siempre son lingüísticos, sino también simbólicos, iconográficos y evocadores, pero que no tendrían eficacia si los receptores no los reconocieran o pudieran interpretar y de ahí surge la vocación de esta investigación: comprobar que los mensajes contienen referencias a mitos clásicos y los receptores las decodifican con el mismo significado de los emisores, porque en ambos comparten las mismas estructuras primordiales con sus propias referencias culturales.

En consecuencia, podemos percibir una categoría de conceptos o contenidos que comparten emisor y receptor, que pretendemos conocer con más detalle en esta investigación para comprender a la vez cuáles son esos contenidos que tanto importan a los públicos, que sólo se perciben en un análisis y que bien pudieran corresponder a los llamados contenidos arquetípicos.

\subsection{Retórica y publicidad}

Retórica y publicidad mantienen un vínculo muy estrecho que se pone de manifiesto en la mayoría de los anuncios dado que "todas las realidades son objeto de la retórica en cuanto también lo son de la comunicación, pero la retórica no es posible sin la comunicación. No hay retórica sin discurso. En el origen de la

ICONO14 | Año 2014 Volumen 12 N 1 | ISSN: 1697-8293 | DOI: ri14.v12i1.549 
retórica está la necesidad de comunicar" (García García, 2007, p. 169), y comunicarse con sus públicos es lo que pretenden todos los anunciantes. Por lo tanto, la retórica tienen un papel fundamental en el proceso de creación de los mensajes publicitarios hasta el extremo de poder afirmar que "el proceso publicitario es un proceso retórico" (Moliné, 2003, p. 250) y su valor en la creación de los mensajes es incuestionable ya que "la retórica es, en suma, el repertorio de las diferentes maneras con las que se puede ser 'original" (Durand, 1972, p. 110).

Aunque no nos demos cuenta, los mensajes publicitarios muestran una gran diversidad de figuras retóricas; esto es así, independientemente de que tanto el creador del mensaje como el receptor del anuncio sean conscientes de la presencia de estos recursos ya que su utilización y aprendizaje forma parte de nuestra participación en la vida social (Baños, García y Ramírez, 2009). Recurrir a la retórica se convierte en una herramienta fundamental para alcanzar los objetivos de comunicación en un contexto determinado, algo que pone de relieve Lausberg cuando afirma que la retórica es "un sistema más o menos estructurado de formas conceptuales y lingüísticas que pueden servir para conseguir el efecto pretendido por el hablante en una situación" (Lausberg 1975, p. 13).

A pesar de que la retórica tiene una antigüedad de 2.500 años, actualmente, con la nueva retórica se adaptan las técnicas de argumentación clásicas a los procedimientos de persuasión actuales (Millán, 2003-2004) recuperando el receptor un papel fundamental en el proceso. La causa de esta modernización de la retórica los sitúa Spang (2005) en los cambios sociales y tecnológicos que se han producido en las últimas décadas.

Desde su origen, el principal objetivo asignado a la retórica ha sido el de persuadir al público (San Nicolás, 2005; Spang, 1997), algo fundamental en publicidad donde lo normal es intentar influir en las decisiones que toman los individuos en relación con un producto, marca, etc. recurriendo, frecuentemente, a las figuras retóricas poniéndolas al servicio de los objetivos publicitarios y de la eficacia del mensaje. Por lo tanto, la retórica no es un simple ornamento para los mensajes publicitarios, sino que, además, se debe ver como una herramienta para elaborar los sentidos de los anuncios (Arroyo, 2005). 


\subsection{Narrativa publicitaria}

Cuando nos referimos a la narración lo estamos haciendo de la representación, organizada de una forma intencionada, de un hecho compuesto por acciones y acontecimientos -que pueden ser reales o ficticios- llevados a cabo por sujetos en un espacio y en un tiempo determinados (Chatman, 1990, Bordwell, 1996, Lothe, 2000; Prosper, 2004).

A pesar de los diferentes enfoques teóricos, hay un acuerdo generalizado en que una narración implica, esencialmente, dos niveles: «algo» ocurre (es historia) que se cuenta de una forma determinada (discurso). La suma de estos dos niveles constituye el relato.

De este modo, en el relato se integra una expresión (el discurso) y un contenido (la historia narrada). A través de un relato concreto se le proporciona al espectador una representación determinada de una historia que se desarrolla en un tiempo y lugar determinados. Por lo tanto, una misma historia se puede narrar recurriendo a diferentes construcciones discursivas (dando lugar a distintos relatos), de tal forma que se puede afirmar que la narración se muestra como una estructura compleja en la que determinados factores o elementos se relacionan entre sí (Chatman, 1990).

Los factores fundamentales, representados en el relato, que definen una historia son: sucede algo, a alguien (personas, animales, objetos, en algún espacio ubicado geográfica y temporalmente (el tiempo está unido indisolublemente al espacio). En otras palabras, los elementos que construyen y definen todo relato sobre una historia determinada son: sucesos, personajes y escenarios.

Los elementos que forman parte de un anuncio pasan a ser componentes o elementos del relato en la medida que, según los criterios del autor, son seleccionados y organizados en una trama y estructurados en función de su intensidad dramática" (Rodríguez y Baños, 2010, p. 36). Es decir, una determinada historia puede dar lugar a diferentes relatos dependiendo de muy diversos factores (tipo de anunciante, equipo creativo, estilo de comunicación, categoría de producto, etc.), 
entre los cuales está la estrategia creativa de la campaña ya que "el fin último de la narrativa publicitaria no es el relato en sí mismo, sino el relato al servicio del producto, servicio, acción... para los que fue concebido" (Moreno, 2003, p. 41).

Para el receptor, los estímulos recibidos a través de los ojos suelen aparecer como representación exacta de la realidad, es decir, que se les supone carácter denotativo, aunque la naturaleza del código icónico sea casi tan compleja y elaborada como la del verbal; lo que es cierto es que la imagen y el sonido deben ser interpretadas como sustancias expresivas.

Sin embargo, la imagen no constituye la reproducción exacta y analógica de la realidad y en ella se puede detectar y analizar siempre dos clases generales de signos:

- los literales, de identidad y de semejanza y

- los no perceptibles en la visión directa de la realidad y sí en la imagen (atribuibles a fenómenos técnicos, ópticos o químicos del medio fotográfico...).

En sus diversas variantes: fija, en movimiento, muda, combinada con sonidos o discursos..., la imagen ha ejercido siempre poderosas influencias sobre el comportamiento humano, dado que constituye la vía principal (o al menos la más inmediata) de concreción de la emociones. Las imágenes, más como vehículos de símbolos (es decir, como símbolo connotado) que como representación objetiva de la realidad, constituyen los recursos ideales para la persuasión y la implantación de los modelos y pautas de conducta deseados, puesto que el ser humano las procesa a partir de premisas basadas en la intuición y en la emotividad, a diferencia de lo que sucede con el lenguaje verbal, mucho más abstracto y asimilado mediante operaciones lógico-racionales.

\subsection{Iconología e iconografía}

Atendiendo a la etimología del término, “la iconografía podría definirse como la disciplina cuyo objeto de estudio es la descripción de las imágenes, o como han 
señalado algunos autores, la escritura en imágenes" (Rodríguez López, 2005, p. 2). González de Zárate considera que, actualmente, la iconografía se entiende como "la ciencia que estudia y describe las imágenes conforme a los temas que desean representar, identificándolas y clasificándolas en el espacio y el tiempo, precisando el origen de las mismas y su evolución" (1991, p. 16), su ámbito de actuación en cinco puntos: Descripción, Identificación, Clasificación, Origen y Evolución; y se diferencia con claridad lo que se puede entender como "motivo" de lo que es un "tema" iconográfico.

De todo este proceso se deriva una catalogación descriptiva sobre las diversas formas de representar un mismo tema. De ese catálogo se deriva una interpretación de sus significados, obteniendo un registro de significaciones que dichos símbolos han obtenido culturalmente y permitiendo la comprensión de su uso en determinadas producciones artísticas como aportación de contenidos morales, sociales, cívicos y naturales.

La iconología tiene como ámbito de investigación la formación, transformación y contenido de las imágenes, de las representaciones figuradas como antítesis. Esta disciplina surge como complemento a los formalistas y forma una unidad con la iconografía.

La investigación de los símbolos culturales y su reflejo en obras artísticas y documentos audiovisuales, permite complementar el análisis semiótico de las creaciones publicitarias que los incorporan. La iconología aplica su interpretación a personajes, narraciones, tiempos, estructuras, músicas... del objeto de estudio en aquellos aspectos que los diferencia de su significado en la vida real actual. Para Rodríguez López, históricamente, “las imágenes han ejercido un gran poder de sugestión en todas las culturas; basta con hacer una reflexión sobre las imágenes publicitarias en la actualidad para comprender lo significativo que puede llegar a resultar ese poder" $(2005$, p. 3).

Panofsky (1939) estructuró una metodología para la realización del análisis iconográfico-iconológico; se trata de un análisis formal que conlleva un análisis de las distintas capas de significado. Ese análisis formal y estético nos interesa pero 
sobre todo nos interesa identificar los motivos que llevan a incluir esos elementos en una obra artística y también la ausencia de ellos.

El nivel de significado intrínseco o profundo sería propio de una investigación de la psicología de masas, no es por tanto el que pretende esta investigación que tiene como finalidad el análisis que Panofsky (1939, p. 36) denomina "fáctico y expresivo" es decir, constatar la presencia de esos elementos iconográfico e iconológicos en piezas publicitarias actuales, lo que confirmaría la hipótesis de que hoy la publicidad contiene esas formas arquetípicas subconscientes que subyacen en el hombre de forma continuada a lo largo de toda nuestra cultura occidental, como expresión de un único discurso que une a sociedades de todos los tiempos en la misma duda o preocupación existencial.

Por supuesto, constatar la presencia de arquetipos lleva a otras consideraciones más de fondo que incluiremos en el capítulo de conclusiones generales como producto de la reflexión que esta investigación produce. Siguiendo el método de Panofsky sobre Iconología (1939) y sus teorías sobre la formación de imágenes, arquetipos figurativos, su evolución a través del tiempo y del espacio, y su papel simbólico, según resume Gutiérrez San Miguel en su estudio sobre esta materia (en García García, 2006, p. 147), realizaremos tres niveles de interpretación de los mensajes publicitarios:

Pre-iconográfico: Fase básica, basada en la interpretación cotidiana, casi intuitiva del mensaje analizado, en la que se perciben los elementos recogidos como tal.

Iconográfico: Participan las experiencias culturales del receptor o espectador.

Iconológico: Estudio profundo de la obra: contexto, intenciones políticas, sociológicas, simbolismos, metáforas, elección de un estilo u otro...

La imbricación de la Iconología con la Semiótica permite contemplar la narración publicitaria audiovisual como un texto que tiene un significado y un significante, con todo lo que ello implica y que se analiza en la primera parte de análisis, $\mathrm{y}$, en un segundo nivel, aflora una lectura que procede de los procesos perceptivos 
del receptor, captando determinados estímulos visuales o determinados conceptos instalados en nuestra cultura de forma paralela, lo que evidencia una mayor riqueza del contenido del mensaje y que este no puede ser leído exclusivamente por sus ingredientes figurativos. Las cualidades expresivas de símbolos y signos culturales forman parte de los recursos del autor para comunicar y expresar ideas.

Para José Luis León, “la cultura simbólica se sitúa afuera de las coordenadas del pensamiento racional, tanto clásicos como contemporáneos, marcada por el principio de no contradicción". (León 2000, p. 25)

\section{Materiales y métodos}

El objetivo de este trabajo es demostrar la pervivencia de arquetipos culturales en los relatos publicitarios de perfumes, cuya estructura narrativa y retórica vehicula un contenido que reinterpreta el mito de Afrodita a partir de símbolos e iconos culturales.

La analogía, como principio hermenéutico, nos transmite el poder de lo subjetivo dando un simbolismo visible a un sentido invisible y un fenómeno singular que es divinizado.

La narración audiovisual se nutre de situaciones recreadas o ficción, de escenarios reales, conversaciones cotidianas y espontáneas, pero también de símbolos culturales, unas veces intencionalmente escogidos y en otras ocasiones sin tener en cuenta su significado, por lo que podemos hablar de dos niveles de significación, el intencional y el consolidado.

La pieza publicitaria recogida en esta investigación es representativa de los anuncios audiovisuales de perfumes y tiene la cualidad de haber gozado de gran éxito durante años y seguir vigente en los medios de comunicación en 2012 y es objeto de este trabajo para mostrar un modelo de análisis de contenido cuyos resultados nos hablarán del significado para el consumidor, tanto a nivel literal o consciente, como a nivel simbólico o inconsciente, y el método que seguiremos

ICONO14 | Año 2014 Volumen 12 NN $^{\circ}$ | ISSN: 1697-8293 | DOI: ri14.v12i1.549 
será el de la interpretación literal y alegórica de las imágenes.

La analogía va a ser el factor recurrente en este análisis de una pieza publicitaria.

\subsection{Metodología}

Se ha llevado a cabo, previamente a éste análisis, y dentro de la tesis doctoral "Mitos y arquetipos de la publicidad audiovisual de perfumes" (Fernández, 2010, p. 233-237), una clasificación de 150 anuncios de perfumes femeninos, masculinos y unisex, de alta gama, exhibidos entre 2000 y 2012, porque constituyen en sí mismos una tipología de publicidad que a falta de un calificativo más idóneo, hemos determinado en calificar de arquetípica, entendiendo por arquetipo, figuras preconscientes que el ser humano proyecta en todas sus producciones.

La clasificación se ha llevado a cabo siguiendo el siguiente procedimiento:

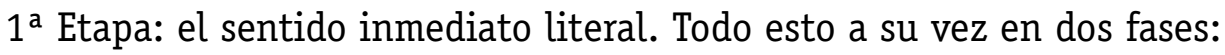

a) el sentido literal-literal de la narración: la historia narrada en el texto

b) el sentido literal-estratégico, la estrategia comercial inherente al anuncio, el beneficio que se ofrece al consumidor, la promesa, el posicionamiento del producto, basado en atributos tangibles e intangibles percibidos por el consumidor.

$2^{\mathrm{a}}$ Etapa: El sentido alegórico: el elemento del anuncio pasa a ser considerado de modo simbólico: los sujetos son considerados como representantes de grupos sociales o humanos, los productos pasan a ser protagonistas de acciones y a convertirse en símbolos.

$3^{a}$ Etapa: reconstrucción del sentido tropológico: unificar distintos anuncios que siguen un mismo fin, o que están emparentados por el servicio común a un mismo valor, más allá de la inmediata intencionalidad comercial. Este es el plano más profundo que traspasa la intención estratégica del autor para hacer llegar a la 
audiencia mensajes que se interiorizan.

El análisis de los mensajes publicitarios de perfumes (García, Baños y Fernández, 2011), nos permite deducir que los perfumes se promocionan mediante narraciones subjetivas y fantásticas que reproducen relatos míticos y que contienen referencias a arquetipos culturales concretos; en términos generales, podemos decir que la publicidad de perfumes actualiza los mitos clásicos, adaptándolos a la época actual y a los públicos a los que se dirige.

Siguiendo a Francisco García García (2006), nos fijamos en la Estructura Narrativa, distinguiendo enunciado, enunciación, formas como los personajes, el espacio, el tiempo y las acciones, y las distintas expresiones de estos elementos, para lo que acudiremos a los distintos recursos audiovisuales, siempre centrados en los elementos significativos que aportan contenido al mensaje, y evitando todos aquellos aspectos técnicos o de montaje, salvo que aporten o refuercen el mensaje del relato persuasivo.

Se trata de una análisis de contenido en el que imbricamos un análisis iconológico.

El anuncio audiovisual de la marca J'Adore de Dior, que se comenzó a exhibir en 2008, cuando se lanzó el perfume, y todavía se exhibe en la actualidad, protagonizado por la actriz Charlize Theron, es el elegido para mostrar el modelo de análisis que proponemos.

\section{Resultados}
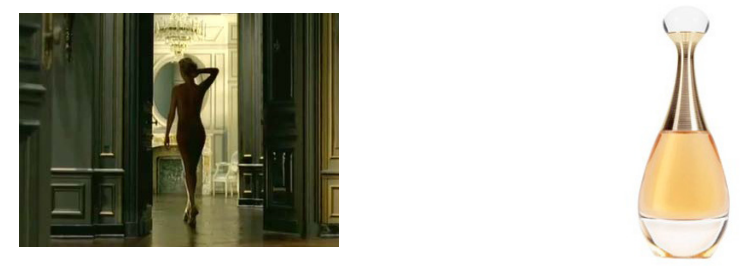

ICONO14 | Año 2014 Volumen $12 N^{\circ} 1$ | ISSN: 1697-8293 | DOI: ri14.v12i1.549 


\subsection{Elementos de clasificación}

\subsection{Ficha}

\begin{tabular}{|l|l|}
\hline Producto anunciado & Perfume femenino J'Adore \\
\hline Marca & Christian Dior \\
\hline Target Group & Mujer madura, >30años, clase alta, urbana \\
\hline Posicionamiento en el mercado & Alta perfumería - lujo. \\
\hline Estilo del producto & $\begin{array}{l}\text { Femineidad, sofisticación, genuino, exclusivo, deslum- } \\
\text { brante, luminoso, divino, único. }\end{array}$ \\
\hline Estilo de vida del target & $\begin{array}{l}\text { Mujeres con experiencia, activas sociales, clase alta, se- } \\
\text { guras de sí mismas, autónomas económica y emocional- } \\
\text { mente, cuya principal preocupación es su libertad perso- } \\
\text { nal. No tiene un compromiso permanente con una pareja } \\
\text { sino que es independiente. }\end{array}$ \\
\hline Formato del anuncio & Spot tv. 45" \\
\hline Año de creación & 2008 (en exhibición hasta 2012) \\
\hline
\end{tabular}

Fuente: Elaboración propia

\subsection{Género y resumen de contenido}

El spot para televisión de la marca J'Adore de Christian Dior, protagonizado por la actriz Charlize Theron, adopta una forma de narración dramática en la que triunfa la seducción natural femenina y se rinde culto a su belleza. El spot narra una secuencia de la intimidad de la protagonista, a quien situamos en un edificio de estilo elegante y parisino que se presenta al inicio, e inmediatamente contemplamos a una bella mujer que acaba de entrar en su apartamento, con el pelo corto y dorado, de estilo elegante y glamuroso, y mientras se adentra en la vivienda, atravesando puertas abiertas y estancias clásicas, de tono dorado, se va desvistiendo, comenzando por los pendientes, los brazaletes, el vestido y... sin transición, pasamos a verla desnuda, de espalda, atravesando la última puerta, con los tacones de aguja todavía puestos, caminando con la desinhibición propia de quien se encuentra en la intimidad, libre y a gusto consigo misma, al margen de cualquier convencionalismo social. Al final aparece en sobreimpresión el envase del perfume y una voz femenina, pronuncia su nombre de forma sugerente: J'Adore. 


\subsection{Estrategia creativa}

Renovar el significado del mito de la diosa Afrodita.

El concepto de la comunicación es el mito de la mujer que es pura sensualidad, creatividad y belleza, como el mito de Afrodita, ya encarnado en las actrices mencionadas, y al final se dice que J'Adore es su perfume, diciéndolo en un doble sentido porque el propio nombre define la esencia de ese mito femenino que adoran o admiran muchos hombres y mujeres. Se construye así una narración cuya estrategia consiste en despertar el recuerdo de ese mito en la mente de los receptores, reconocerlo y admirarlo, para asociarlo finalmente al perfume, cuyo envase tiene la forma del cuerpo de la mujer.

\subsection{Estructura narrativa}

\subsubsection{Contenido}

Escena de breve duración en el tiempo real y escasos elementos narrativos pero muy potentes en su capacidad de evocación. Una única protagonista, un mismo escenario que se recorre, música y voz directa de la protagonista enunciando el perfume.

\section{Trama y subtrama}

La trama principal es mostrar la belleza de la mujer en estado puro, desnuda y natural, sin adornos, joyas, con el pelo desordenado. Sus gestos contribuyen a que su belleza, además de física, se perciba en su actitud ante la vida como ser libre, instintivo y natural. La subtrama tiene que ver con el tipo de vestido y el entorno en que se mueve, un apartamento de lujo, clásico y enorme, que nos sitúa en un entorno de glamour, lujo y exclusividad, casi divino, si bien las estancias por las que pasa la mujer están sin iluminar, por lo que es un aspecto secundario o no imprescindible pero que fija, sin lugar a dudas, el perfume que se anuncia en un entorno propio de la clase social alta o, si estuviéramos en la Antigüedad Clásica, el entorno propio de los dioses. 


\section{Tipo de relato}

Se combinan en este relato elementos de tipo denotativo y connotativo; denotativos como los descritos en la subtrama para la decoración de las estancias en las que se desarrolla la acción, calculada para situar el producto en un entorno aspiracional como es el de la alta perfumería y la alta costura francesa. La acción que configura la trama, tiene carácter connotativo, ya que la actitud de la mujer es la de desprenderse de piezas de su vestuario como si encorsetaran su libertad o le impidieran ser ella misma. Tienen por tanto un significado connotativo: la belleza natural está por encima de todo lo que es creación humana o terrenal. Belleza absoluta frente a belleza relativa o temporal. Podríamos decir, asimismo, que los gestos de tirar las joyas al suelo tienen un carácter simbólico y otorgan a la protagonista la condición de diosa; ella, en sí misma es completa, perfecta, un elogio de la creación natural. Contiene también un valor simbólico, en la narrativa audiovisual erótica moderna, la imagen de la mujer desnuda calzando tacones de aguja; la vemos de espalda, la imaginamos de frente, como la vimos unos segundos atrás, y los tacones la hacen parecer más poderosa y dominando el escenario, son un símbolo de seducción erótica.

\section{Personajes y roles}

El anuncio del perfume J'Adore tiene un personaje único y protagonista, la mujer cuya silueta veremos al final, similar al envase del perfume. Es bella, alta, de pelo dorado, corto y natural, lo que le hace parecer libre, moderna y rebelde. El vestido y las joyas de las que se desprende le hacen parecer una diosa que por un momento ha utilizado esos elementos pero que no los necesita porque se mueve con determinación mientras se quita todo lo que lleva puesto sobre el cuerpo y lo abandona en el suelo.

\section{Apariencia y dirección mantenida de los personajes}

No le importa nada lo material, sigue su instinto y disfruta de su cuerpo sin complejos y sin necesidad de adornarlo, lo que refleja una personalidad segura de sí misma, atrevida, desinhibida y afortunada porque tiene todo lo que necesita. Se desenvuelve en un entorno privilegiado, lo que nos indica que alcanza todo lo que desea. Utiliza sus armas de seducción femenina con inteligencia. Es un prototipo de belleza pura, sin condicionantes culturales o sociales. 


\section{Interacciones de la trama y subtrama con el producto $y / o$ servicio}

La bella mujer protagonista interacciona en la trama con el producto al mencionar su nombre y a continuación aparece el perfume en su envase con forma de cuerpo de mujer. La deducción que se deriva de esa interacción es que ella tiene un elixir que la ayuda a ser tan bella como natural y libre; es decir que el aroma del perfume queda definido por las características de la mujer-diosa. La sub-trama completa la definición del ámbito de actuación social del perfume: en entornos donde predomina el glamour, el lujo, lo exclusivo, la libertad sin condicionantes. La sub-trama define el nivel económico y social al que pertenece o aspira el consumidor seducido por este aroma definido en la trama.

\section{Interacciones entre los personajes con el producto}

El perfume, en su envase, encuentra su personificación en la mujer protagonista. No es una interacción sino una transmisión de atributos de identidad.

\section{Valores generales exaltados de los personajes}

La actualidad de la actriz protagonista era máxima en el año de estreno del spot (2008) ya que obtuvo un premio Óscar como actriz protagonista por la película Monster . Sigue teniendo popularidad y aporta modernidad a la marca de perfume de la casa Dior. Además es una actriz americana que responde al prototipo de la mujer de éxito actual: bella, famosa, sexy, rica... la encarnación social de lo que sería propio de diosas en la antigüedad. El valor principal es la belleza de su rostro y la esbeltez del cuerpo, en segundo lugar se exalta su carácter libre y dominante, y en tercer lugar se aprecia la importancia del nivel económico, expresado en el entorno en el que se mueve, la vivienda clásica, grande, lujoso y elegante como referente para los públicos en general, de palacios y viviendas de personas de alto status.

\section{Valores generales exaltados en el producto $y / 0$ servicio}

Cuando aparece el perfume en su envase es justo después de que la protagonista pronuncie despacio y suavemente su nombre, con lo que se le otorga un carácter erótico o sensual muy acentuado. A continuación vemos la imagen de la mujer desnuda de espalda, con lo que la característica de belleza pura y libre se traslada al perfume, cuyo envase se parece en la forma a la mujer y así lo volvemos a com-

ICONO14 | Año 2014 Volumen 12 NN $^{\circ}$ | ISSN: 1697-8293 | DOI: ri14.v12i1.549 
probar en la última imagen del anuncio, de nuevo el envase del perfume con su líquido tan dorado como el pelo corto de la mujer.

\subsubsection{Forma de expresión}

\section{Base de la estructura persuasiva}

La historia narrada se resuelve mediante una elipsis y un cambio de acción en el que destaca un claro paralelismo de forma entre el bello cuerpo de mujer y el envase de perfume. La imagen de la mujer protagonista en su escenario de elegancia clásica, se obtiene mediante planos generales que permiten contemplar la totalidad de la mujer y, lo más importante, sus acciones, sus movimientos para quitarse y tirar al suelo, con gesto airado, los objetos. De los planos generales pasamos a un plano medio en que la atención se fija en sus labios que susurran J'Adore y se ve parte de su cuerpo desnudo pero sin llegar a mostrarlo. En ese momento se ha alcanzado el punto álgido de erotismo a través del desnudo paso a paso que hemos ido presenciando y ahí, exactamente, es donde aparece el envase del perfume, cuya forma similar al cuerpo femenino parece que la supliera por unos segundos, para dejarnos ver un final de espectáculo que mantiene alto el nivel de erotismo anterior, al verse de nuevo su cuerpo desnudo, de cuerpo entero, aunque ahora de espalda, en un plano simétrico a los iniciales, como si la cámara no se hubiera movido del sitio sino sólo la hubiera visto pasar.

\section{Vehiculación de los elementos persuasivos}

El elemento persuasivo más importante es el cuerpo de la mujer que nos remite al perfume por la forma. Los labios de la mujer y su voz pronuncian su nombre otorgándole una gran carga de sensualidad. El rechazo a las joyas y adornos nos explica indirectamente que la esencia del perfume es la naturaleza en estado puro, como el cuerpo desnudo de Charlize Theron y, finalmente, las altas puertas abiertas nos informan de que es un perfume para mujeres sin tabúes, libres, y el mobiliario que adivinamos en las habitaciones, por sus sombras, nos comunica que es un perfume de gama alta, con clase, y del nivel de vida que identificamos con el lujo, los privilegios y la vida relajada. 


\section{Base de la seducción}

El erotismo y la seducción son las armas que instrumentan la persuasión del mensaje publicitario sobre el receptor. Al comienzo la mujer lleva un vestido muy ceñido, escotado y sexy, lo que es un prólogo de lo que veremos después. La imagen de la mujer que se desnuda poco a poco podría resultar un tópico con otra música y otros gestos más intencionales. En este caso, esa seducción y erotismo vienen acompañados de una actitud resuelta, de dominio sobre sus actos, decidido y libre, de la actriz protagonista. Ella es el perfume y se comporta como se supone que es el perfume, y así debemos entenderlo cuando se intercala la imagen del perfume con el de la mujer en el momento de máxima carga emocional del anuncio, en los segundos finales. - Base retórico-connotativa Todo el relato es una gran metáfora de los aromas con que se ha elaborado el perfume J'Adore, cuyas notas, más allá de sus componentes florales, químicos o destilados, evocan la esencia de la femineidad física, puramente bella, natural y digna de adoración; esta es la base de la metáfora: no el perfume, sino lo que evoca, que es un anhelo humano. Esta metáfora se refuerza con una personificación del producto en su diosa y un paralelismo producto-mujer-producto.

\section{Base simbólico-connotativa}

Las casas de perfumería francesa mantienen desde hace décadas la hegemonía sobre la categoría de perfumes de lujo y con este anuncio, la casa Dior reitera la pertenencia a ese grupo de la casa matriz y del perfume en particular que se anuncia; la base simbólica se sustenta sobre la evocación del lujo, el glamour, la posesión de la belleza y la capacidad para utilizar todo ello, lo que socialmente se atribuye hoy en día a una clase social privilegiada.

\section{Arquetipos narrativo-persuasivos}

La mímesis de fragmentos del cine clásico americano de los años 50 en el que importantes actrices se convertían en el centro de interés, y eran imitados por las mujeres, por sus cualidades de mujeres fuertes, bellas, deseadas, plenas de sensualidad y vidas amorosas intensas, son la fuente de inspiración remota de este relato publicitario que lleva a la mujer a la condición de diosa, mostrándola en su máximo esplendor, sin complejos ni justificaciones, con un tono de admiración sincera del prototipo.

ICONO14 | Año 2014 Volumen 12 NN $^{\circ}$ | ISSN: 1697-8293 | DOI: ri14.v12i1.549 


\section{5. La acción narrativa}

La acción se plantea de forma directa desde el comienzo del relato, centrando la imagen en los movimientos de la mujer, entonces aparece el perfume, a continuación aparece la mujer durante unos breves segundos, alejándose sobre sus tacones, desnuda; vuelve a aparecer el envase en ese momento y así, mediante la pronunciación de su nombre, se cierra el relato, de forma tan clara y directa como comenzó.

\section{Espacio narrativo}

El espacio elegido es un interior de una vivienda. Es un espacio cuyo aspecto y mobiliario denotan buen gusto y clase social alta. El interior de un lugar nos habla de la intimidad, que es el espacio emocional en el que vemos a la protagonista desenvolverse de forma natural. La cámara, quieta en un ángulo, aumenta la sensación de que estamos invadiendo su privacidad, y eso aumenta la curiosidad del espectador. El estilo de este lugar se percibe levemente porque está en penumbra, lo que no impide que podamos contextualizar la acción en un entorno social de clase alta; son datos que confirman o completan lo que percibimos a través de la protagonista, que estamos en un ámbito no convencional.

\section{Espacio representado}

El espacio narrativo cobra un significado más centrado en la intimidad de la protagonista al ser representado en penumbra; en ese espacio se siente más libre y natural, si cabe, al eliminar todo resto del exterior, quitándose el vestido y las joyas que abandona en el suelo.

\section{Espacio imaginado}

El espacio definido con formas esbeltas, suaves e intemporales, evoca en la imaginación del receptor los escenarios majestuosos que han sido sede de personajes poderosos, ficticios o míticos, palacios o templos, lo que traducido a la actualidad serían las viviendas de lujo de actores, actrices, millonarios y gente famosa, todos poderosos económicamente y con residencia en ciudades como París, Londres, Nueva York o Los Angeles. 


\subsection{El sujeto de la enunciación}

Se trata de un perfume de la marca francesa Dior, que inició su desarrollo a mediados del s. XX como marca de Alta Costura para la mujer, después se introdujo en la perfumería, los complementos de moda y belleza. El perfume denominado J'Adore aparece en el mercado en el otoño de 2001, siendo su creador François Dernachy, quien más tarde revisa el perfume por indicación del director de la marca en 2004, el diseñador John Galiano; el resultado es una reinterpretación del emblemático aroma floral de J'Adore que explora la tradicional combinación Neroli/ Bergamota y le añade una inesperada nota de Magnolia, que se constituye en una parte esencia del aroma del perfume a partir de ese momento. El anuncio publicitario del perfume contiene algunos elementos definitorios de su carácter y personalidad, como la presencia del color dorado en las estancias y en las habitaciones como encarnación de todo el lujo y la sensualidad del perfume para simbolizar, según John Galiano, el privilegio que siente la mujer cuando lleva el perfume. La protagonista es una figura vicaria de un arquetipo femenino que forma parte del imaginario sexual femenino y masculino, como una representación de las mujeres que hoy en día triunfan, apoyadas por los medios de comunicación, y se convierten en referente como grupo social de éxito social y personal.

\subsection{El tiempo del relato audiovisual}

La narración es breve y tan sólo un poco más corta que si se filmara en tiempo real la acción. Podemos hablar de una escena, pues prácticamente es equivalente el tiempo narrativo al tiempo real. Eso aporta credibilidad a los hechos, porque al mismo tiempo, la situación resulta natural y cotidiana para el arquetipo de mujer representado, que está presente con mayor o menor intensidad en el interior de toda mujer. La trascendencia del relato tiene un eco intemporal, eterno, al representar unos aspectos femeninos que han discurrido transversalmente por la historia humana. Es una acción fácilmente transportable a distintas etapas históricas. El significado del relato está determinado, además de por la acción en sí misma, por el uso de las modalidades temporales que registra: relato ficcional, con la propuesta de imitar a la mujer, y relato cosmológico, pues la situación, la emoción y el espacio representados tienen carácter eterno. 


\section{Posibilidades imaginativas del uso del tiempo narrativo}

$\mathrm{El}$ anuncio de J'Adore utiliza metafóricamente el tiempo, al ser compatible con cualquier estilo de vida de mujer, siendo una metáfora de la esencia femenina. El tiempo no es el tema de la historia sino su soporte de credibilidad. Además, la concreción del relato en una escena permite percibirlo como pequeñas partes de la vida de cualquier mujer en su tiempo de intimidad. Esta es la segunda utilización del tiempo, la personal, la de la naturaleza no cronológica, sino emocional, que tiene muchos momentos y en este relato se materializa uno en concreto.

\subsection{El lenguaje narrativo-audiovisual}

El lenguaje audiovisual es austero en los movimientos de la cámara, cambiando el foco, pero no la posición del mismo. El sonido es importante, acompañando en los planos generales una suave música y la voz de la mujer, que susurra, se va percibiendo mientras se acerca a la cámara, hasta oír claramente su voz, coincidiendo con el plano medio. La voz susurra el nombre del perfume varias veces, escuchándose claramente sobre la imagen del perfume, en el inserto de la imagen fija del envase, y en el cierre. Es interesante esa utilización porque la voz actúa como transmisor de las características de la mujer al perfume. La imagen del perfume y el lenguaje verbal se complementan cerrando el mensaje publicitario.

\section{Recursos estilísticos}

- La aliteración: la repetición del nombre del perfume, con el mismo tono de voz, por la protagonista, es un elemento importante que distingue al anuncio de otros que utilizan voz en off o un texto; es importante la repetición y el tono sugerente de la misma, para acabar rompiendo la aliteración con el nombre de la marca Dior, pero en el mismo tono del nombre del perfume.

- Paralelismo: Se ejecuta a través de la forma en la narración audiovisual. En el comienzo, vemos a la mujer de frente, al final vemos a la mujer de espalda. Es un paralelismo en la estructura que abre y cierra el anuncio.

- Metonimia: Los gestos de la mujer protagonista, tirando al suelo las joyas y el elegante vestido, tienen el significado cercano de librarse de las ataduras sociales, 
culturales, de clase, de moral...y todo lo que pueda ceñir su libertad. Es clara la interpretación porque las acciones van acompañadas de un gesto de liberación, sin rabia ni fuerza, pero con determinación.

- Sinécdoque: Consiste en atribuir todos los rasgos de personalidad de la mujer protagonista al perfume, tomando el total de su personalidad como la definición del aroma de J'Adore y las sensaciones que produce.

- Comparación: consiste en la presentación de dos elementos con el fin de que se puedan comparar sus cualidades y propiedades: el perfume y la personalidad de la mujer que lo encarna.

- Metáfora: es una variedad de la comparación anterior pero más acentuada y consiste en sustituir, en unos planos, el cuerpo de la mujer por el envase del producto, con el que se establece una relación de semejanza. Menos evidente pero consecuencia de lo anterior, es imaginar que el aroma del anuncio equivale a la personalidad de ella y suponemos sus rasgos florales (sensualidad), frescos (libertad) e intensos (carácter decidido y seguro).

- Símbolo: Quitarse los adornos corporales es un gesto simbólico de rechazo a lo que no es esencial, rechazo a lo que limita u oprime. Quitarse el vestido, mostrarse desnuda, es un símbolo de autenticidad, de verdad. Vestir con zapatos de tacón escotados y frágiles, de tacón fino y alto, es una clara atención a la coquetería, el gusto por la seducción y las metas altas.

- Juegos de ideas o juegos de palabras. El mensaje publicitario juega con el nombre del producto y así, cuando dice J'Adore por primera vez, interpretamos que está hablando de ella misma, de lo que quiere o adora hacer, lo que es ratificado por su actitud decidida. Después vemos que es el nombre del perfume y entendemos que adora ese aroma, esas sensaciones que provoca, quedando en la interpretación final todo unido. 


\subsection{Interpretación iconológica}

En el spot de Dior, la protagonista-afrodita, es expresión misma de la sensualidad, como sugiere su forma de andar, el cabello dorado, ondulado y libre, aunque corto, no largo como en el mito, lo que entendemos como una actualización del personaje.

\section{Iconografía}

El hecho de que se despoje de todo lo que lleva sobre el cuerpo, subraya su naturaleza esencial: es ella misma, sin necesidad de recurrir a ningún artificio. Afrodita nace de las aguas del 0céano, es decir, del inconsciente colectivo, no como niña, sino como la mujer capaz de estimular la creatividad en los otros, inteligente, con personalidad, y libre, como el amante perfecto en la mente de hombres y mujeres.

- Arquetipo del amor carnal: Sexualidad y Sensualidad

El reino de la "amante" es una fuerza poderosa y arquetípica en la mujer de todos los tiempos, reprimida desde la Antigüedad, por razones sociales, culturales y religiosas, lo que convierte a estas mujeres en proscritas o prostitutas. Afrodita se hacía acompañar siempre por Eros y las 3 Gracias: Aglaya, Eufrosine y Talía eran las diosas de la belleza, el hechizo y la alegría. Las Gracias otorgaban a dioses y mortales estos aspectos, pero no sólo eso sino también la elocuencia, la liberalidad y la sabiduría.

- Afrodita y la belleza

La belleza es algo más que un atributo carnal para los griegos. La armonía de las formas, el equilibrio y la estética en conjunto se considera propio de los dioses. La persona o el dios bello goza de un estadio superior, según este criterio.

En su significación espiritual se desdobla en el amor físico y en el amor como sentimiento. Es una mujer-Afrodita a la que solo se puede rendir adoración, y el destilado de su esencia, como un elixir, parece estar en el envase de Dior. 
- Hesíodo señala que nace de una acción brutal: Cronos cortó los genitales de su padre con una hoz para acabar con su despotismo y los arrojó al mar. La mezcla de la espuma con el semen (aphros) produjo una concepción oceánica. Afrodita ya nació adulta, sobre una concha marina. Ese nacimiento es un hecho singular que la sitúa en condiciones de cumplir con su principal función, la de ser embajadora del amor y la pasión. Eros (amor) e Himeros (deseo) la acompañaron ante los dioses en Chipre, quienes la reconocieron como una de ellos. Como musa del amor y el deseo, la promiscuidad es una de sus facetas.

\section{El oro - Entorno dorado}

Estamos acostumbrados a la asociación del elemento "oro" a la riqueza, el lujo, los dioses. En este sentido el perfume se sitúa en el nivel que la propia marca ocupa en el mercado mundial, como una marca de lujo. El nombre del producto, $\mathrm{J}^{\prime}$ adore, abunda en el mismo significado, llevando a interpretaciones variadas, siendo la más afín, "Adorar el perfume" pero también tiene lecturas complementarias como "adorar el lujo", "adorar la libertad"... todas ellas en relación a lo expresado para Afrodita. Jung transcribe la bella explicación del alquimista Michel Maier, en De Círculo Physico Cuadrato, para el cual,

a consecuencia de los millones de rotaciones en torno a la tierra (o inversamente), el Sol ha hilado el oro en ella. El oro, es la imagen de la luz solar $y$, por consiguiente, de la inteligencia divina. El corazón es la imagen del sol en el hombre, como el oro lo es en la tierra (Jung, 1950).

Consecuentemente, el oro simboliza todo lo superior, la glorificación. Se considera expresión de los bienes espirituales y de la iluminación suprema. Las rosas son las flores simbólicas de la diosa, que también se adivinan en el entorno en el que se mueve la modelo. La rosa de oro, ya que todo es dorado en el escenario, es el emblema de la realización absoluta, lo que ya dice suficiente respecto a lo que el spot quiere transmitir a la audiencia: la experiencia con el perfume es comparable a una experiencia sensorial iniciática. La perfección de esta flor es metáfora de la personalidad de la diosa Afrodita.

ICONO14 | Año 2014 Volumen 12 N 1 | ISSN: 1697-8293 | DOI: ri14.v12i1.549 


\section{Símbolos y atributos de Afrodita}

Un cinturón que tenía el don de encender en amores a quien la diosa se lo ceñía. La tortuga fue un símbolo de la Diosa en tiempos primitivos. El delfín fue su atributo en Cnido, donde era adorada como "Diosa del Pacífico Mar". También la paloma, el carnero, el cisne, la rosa, el mirto, la manzana...En Corinto se la representaba armada. La granada es su símbolo de la fecundidad. Eros, conocido más tarde como Cupido, la acompañaba durante la mayoría del tiempo; enamorado de Psique, su unión significa amor platónico o espiritual. Como esposa de Hefestos, Afrodita entra en contacto con la profundidad del pensamiento y con el conocimiento, lo que completa su desarrollo individual. Esta etapa en su vida es definitiva para alcanzar la completitud. De hecho, después de esta unión Afrodita desarrolla su aspecto definitivo: la creatividad.

- Diosa de la creatividad: El adjetivo que más se repite para describir a Afrodita es "Dorada", en relación a su pelo rubio que además, es ondulado y suele caer de forma libre, en un ejercicio de libertad muy sugerente. Las rosas suelen coronarla como guirnalda o seguirla como estela. Ambos símbolos se relacionan con la creatividad. Con estos atributos, inspira sentimientos de amor libre para todos los órdenes de la vida pero sobre todo en el amor carnal.

- Afrodita y la fecundidad: La Granada (púnica granatum) fruto del granado, es el motivo simbólico que relaciona a Afrodita y la fertilidad. Fruto procedente de los Balcanes, Oriente Medio y la India. Desde la antigüedad se ha cultivado este árbol; en tumbas egipcias de 2500 a.C. se han hallado restos de granadas. Los fenicios, los romanos y posteriormente los árabes difundieron su cultivo por toda la región mediterránea.

Los griegos creían que las granadas habían brotado de la sangre de Dioniso. El significado de la granada, según el diccionario de símbolos de Juan Eduardo Cirlot es el siguiente:

El significado prevaleciente de la granada, debido a su forma y estructura interna, dominando sobre la impresión del color, es el del adecuado ajuste de lo múltiple y lo diverso en el seno de la unidad aparente. Por 
eso, ya en la Biblia aparece como símbolo de la unidad del universo. También simboliza la fecundidad. (Cirlot, 1997, p. 236)

Lo que ella inspira, exalta y defiende es el amor físico, la unión carnal. A su paso se cubren de flores los caminos pues Afrodita es "causa primera" de la fertilidad vegetal.

\section{Iconología}

Entonces el halago del aire puro, susurro del cielo azul, le produjo un blando suspiro que repitió estremecido el universo. Toda la naturaleza pareció regocijarse con la presencia de Afrodita, con su nacimiento el mundo empezó a sentir las verdaderas palpitaciones del amor y la alegría del vivir. Hesíodo.

\section{Presencia de iconos o símbolos en el relato}

La mujer protagonista, con su cabello peinado de manera informal, es, por su conducta y aspecto físico, un icono de la modernidad, una mujer libre que es dueña de su cuerpo y su sexualidad. El pelo rubio muy claro, es utilizado como símbolo de la sensualidad femenina, como arquetipo de la belleza más deseada. La actriz no lleva ninguno de los símbolos antes mencionados para la diosa, excepto el aspecto dorado y luminoso de su cabello ondulado y de su cuerpo, lo que en la actualidad resulta evocador de tantas otras encarnaciones de Afrodita conocidas hasta el momento, como Marilyn Monroe o la modelo Claudia Schiffer.

\section{Significado connotado del símbolo}

La mujer Afrodita, simbólicamente, conecta con lo esencial de hombres y mujeres, es la fuente de inspiración de muchas personas que ven un estímulo en esta figura libre de prejuicios y promotora de la creatividad.

El hecho de que tenga las necesidades materiales cubiertas es otro de los símbolos que se desean en la actualidad, como base material precisa para desarrollar una vida plena. No hay duda de que esa no es una preocupación para la diosa. 


\section{Interrelación del símbolo o relato mítico con los personajes}

Las palabras de Hesíodo y la reproducción de la pintura de Boticelli, El Nacimiento de la Primavera, nos conectan con la impresión que produce la protagonista de este anuncio, similar al del nacimiento de Afrodita, ya que suscita la misma conmoción al contemplar su perfecta belleza, su magnetismo y poderosa presencia. En el anuncio sin embargo la mujer hace el proceso al revés que Afrodita cuando esta nace desnuda, cubierta únicamente por su cabello dorado; en este caso, Charlize Theron se va despojando de todo lo que lleva puesto hasta quedar desnuda, el estado natural de Afrodita.

\section{Interrelación del símbolo o relato mítico con la acción}

La acción de despojar al cuerpo de todo cuanto lo adorna para dejar al descubierto la belleza al natural, es compatible con el nacimiento de Afrodita, bella y satisfecha consigo misma, su actitud libre y decidida, en el entorno humano y divino.

\section{Interrelación del símbolo o relato mítico con el tiempo y espacio}

La atmósfera del lugar donde reside la protagonista es intemporal, de carácter clásico, elegante y lujoso. El glamour de un apartamento parisino, es el equivalente actual a la residencia de una diosa. En París se dan cita las mejores modelos del mundo para desfilar con las creaciones de los mejores modistos de la moda, el símbolo internacional más representativo de esta ciudad, por tanto reúne las cualidades más apropiadas para una diosa de primer orden.

\section{Interrelaciones del símbolo o relato mítico con el lenguaje}

Las similitudes en la narración parten de esa protagonista rubia y bella, cubierta de ropa y objetos dorados, como dorado es todo lo que la rodea, al igual que se solía representar a la diosa, desnuda y resplandeciente. Es la forma de describir y expresar el impacto que causa una mujer perfecta, inspiradora de todo tipo de emociones. Como la diosa es adorada, el perfume con forma de mujer, personificación de la diosa, es denominado J' Adore, como una declaración de fe absoluta. La diosa-mujer de anuncio es osada, libre, generosa, única y completa en sí misma, por lo que prescinde de todo lo que no es esencial. Su forma de andar es sensual y su coquetería se manifiesta en permanecer con los tacones puestos. 


\section{Interrelaciones del símbolo o relato mítico con el producto}

El envase del producto, con forma del cuerpo de la mujer-diosa, aparece intercalado entre la imagen de ella desnuda de frente y de espaldas, hacia el final del relato, buscando una identificación entre las cualidades aplicadas a la encarnación de la diosa, y el producto que, como consecuencia, resulta definido como un producto que las mujeres adoran porque les atribuye una fuerza personal y sexual irresistible, despertando su creatividad y su instinto natural.

\section{Conclusiones}

El análisis practicado a la pieza publicitaria seleccionada permite confirmar el objetivo de este trabajo: constatar la presencia de contenidos culturales más profundos que los relacionados con el contexto del propio producto: referencias al arquetipo de la diosa Afrodita. La rencarnación de Afrodita-Venus-Isthar...como prototipo de la sensualidad y la creatividad humanas, es representada en el anuncio publicitario de la marca J'Adore de Christian Dior, en un relato que re-interpreta y actualiza el mito que evoca, utilizando elementos retóricos, simbólicos y literales que conducen a transmitir la promesa de que es un perfume que te hará sentir única, como un despertar de la parte más genuina de la femineidad. El arquetipo se re-inventa en el lenguaje visual a través de un relato que reúne todos los elementos icónicos y de lenguaje visual y verbal esenciales en el mito, y el espectador asiste fascinado a la visión de una escena que tiene mayor capacidad de transmisión del mito en la actualidad porque utiliza los referentes que la sociedad actual ha divinizado: la belleza física, el poder económico, la desenvoltura personal y un escenario también mítico como París.

La publicidad audiovisual de perfumes, representada en esta investigación por el anuncio de J'Adore-Dior, que hemos analizado, presenta características particulares que nos permiten hablar de una categoría de anuncios que podríamos denominar "arquetípicos", tomando la expresión de C. G. Jung (1950), al tratarse de relatos en los que se recrea y actualizan modelos humanos que a través de la historia se repiten y perpetúan con lógicas adaptaciones sociales y culturales. Estas narraciones persuasivas enriquecen su relato con fórmulas elaboradas con 
diferentes recursos retóricos, iconográficos e iconológicos. La adecuación de estos mensajes al producto que representan no se hace describiendo el mismo, el perfume, sino que de forma indirecta se relaciona con conceptos y actitudes propios de dichos arquetipos, provocando una auto-identificación en los consumidores. Se trata de un lenguaje persuasivo muy sugerente, nada racional, con un contenido que podemos denominar universal, que permite la vigencia del anuncio en largos períodos de tiempo, como ocurre con el ejemplo analizado.

Este modelo de análisis, aplicado al conjunto de mensajes persuasivos audiovisuales del sector de la perfumería, nos permite saber qué modelos o arquetipos son los dominantes y confrontarlo con los arquetipos preponderantes en nuestra sociedad actual.

En el anuncio de J'Adore encontramos mucho más que un perfume, un modelo de mujer que hemos identificado con el arquetipo de la sensualidad y la belleza, como la diosa Afrodita, que es mucho más que un modelo femenino, es un concepto, creemos, que engloba todas las características visible y no visibles, el concepto de la creatividad.

La femineidad no es sólo sensualidad, es capacidad creativa, innovación, libertad, celebración de la vida. Lo más significativo del anuncio es el hecho de que la mujer esté satisfecha sin que esto implique la presencia de un hombre; esa es la celebración de ser mujer sin la necesidad de confirmación masculina; un triunfo que sin embargo no se explicita pero explica porqué este anuncio gusta tanto a hombres como a mujeres; la creatividad es una cualidad, y el perfume anunciado se define como un elixir potenciador de la creatividad, mostrando las prestaciones de esta cualidad, en la sensualidad de la protagonista del anuncio.

\section{Discusión}

La metodología de análisis diseñada muestra resultados más novedosos en el apartado del análisis iconológico y habría que determinar si con esta única vía podría constatarse la presencia de arquetipos culturales tal y como lo enunció C.G. Jung (2002). Resultaría asimismo relevante confrontar los resultados con la inten- 
ción de los creativos publicitarios autores del relato publicitario para constatar su carácter inconsciente 0 , por el contrario, consciente y por tanto voluntario.

El análisis retórico y narrativo aporta menos informaciones en el sentido apuntado por el objetivo de este trabajo y podría considerarse complementario pero no decisivo para la finalidad de conocer la base que sustenta el relato; podría sustituirse por un análisis de la argumentación.

\section{Referencias bibliográficas}

Arroyo, I. (2005). Creatividad publicitaria y retórica. Icono 14, n5. Recuperado en http://www.icono14.net

Baños, M.; García, F.; Ramírez, J. (2009). Las palabras en la publicidad. El redactor publicitario y su papel en la comunicación publicitaria. Madrid: Editorial Laberinto.

Bordwell, D. (1996). La narración en el cine de ficción. Barcelona: Paidós.

Chatman, S. (1990). Historia y discurso. La estructura narrativa en la novela y el cine. Madrid: Taurus.

Cirlot, Juan E. (1997). Diccionario de Símbolos. Ed. Siruela: Madrid.

Durand, J. (1972). Retórica e imagen publicitaria. En Metz, Ch., Eco, U, Durand, J, Péninou, G, Morin, V., Du Pasquier, S. et al., Análisis de las imágenes.

Buenos Aires: Editorial Tiempo Contemporáneo, S. A.

Fernández, P. (2010) Mitos y arquetipos en los mensajes publicitarios de perfumes. (Tesis doctoral) Universidad Complutense de Madrid.

García García, F. (2007). Una retórica de la publicidad: De la naturaleza inventiva a la verdad metafórica. Pensar la Publicidad, I (2), 2007, 167-182.

García García, F. y otros (2006), Narrativa Audiovisual. Madrid: Ediciones del Laberinto.

García, F., Baños, M. y Fernández, P. (2011). Estructuras y contenidos arquetípicos en la comunicación publicitaria. Comunicar, XIX (37), 187-194. doi: 10.3916/C37-2011-03-11

González de Zárate, J. M. (1991). Análisis del método iconográfico. Cuadernos de arte e iconografía, IV (7), recuperado en http://fuesp.com/revistas/pag/ 
cai07_conferencia.html

Jung, C. Gustav (1950). Tipos psicológicos. Zurich, 1921, 8a edición.

Jung, C. Gustav (2002). Obra Completa volumen 9/I: Los arquetipos y lo

inconsciente colectivo. Madrid: Editorial Trotta. ISBN 978-84-8164-525-5.

Lausberg, H. (1975). Elementos de retórica literaria. Madrid: Gredos.

León, J. L. ( 2001). Mitoanálisis de la publicidad. Barcelona: Editorial Ariel

Lothe, J. (2000). Narrative in Fiction and Film. New York: Oxford University Press

Milán, P. J. (2003-2004). Publicidad, retórica y sociedad. Comunicación, 2, 115127.

Moliné, M. (2003). La comunicación activa. Publicidad sólida. Barcelona: Ediciones Deusto.

Moreno, I. (2003), Narrativa audiovisual publicitaria. Barcelona: Paidós.

Panofsky, E. (1939). Estudios sobre iconología. Madrid: Alianza.

Prósper, J. (2004). Elementos constitutivos del relato cinematográfico. Valencia:

Editorial Universidad Politécnica de Valencia.

Rodríguez López, M. I. (2005). Introducción general a los estudios iconográficos y a su metodología. Editorial/es: Liceus, Servicios de Gestión y Comunicación, S.L: Madrid.

Rodríguez García, T. C. y Baños González, M. (2010). Construcción y memoria del relato audiovisual. Madrid: Fragua.

San Nicolás, C. (2005). Introducción a la Creatividad Publicitaria. Murcia: ICEUniversidad de Murcia.

Spang, K. (2005). Fundamentos de Retórica Literaria y Publicitaria. Pamplona: Eunsa. 